\title{
Emergency Management of Traumatic Spinal Cord Injuries
}

\author{
Mohammed Maan Abdul Azeez ${ }^{1}$ Luis Rafael Moscote-Salazar ${ }^{2,3}$ Gabriel Alcala-Cerra ${ }^{3}$ \\ Ezequiel García-Ballestas ${ }^{2,3}$ Diego Bustos-Salazar ${ }^{3}$ Guru Dutta Satyarthee ${ }^{4}$ Amit Agrawal $^{5}$
}

${ }^{1}$ College of Medicine, University of Baghdad, Baghdad, Iraq

${ }^{2}$ Consejo Latinoamericano de Neurointensivismo- CLaNi, Cartagena, Colombia

${ }^{3}$ Centro De Investigaciones Biomédicas (CIB), Faculty of Medicine, University of Cartagena, Cartagena, Colombia

${ }^{4}$ Department of Neurosurgery, All India Institute of Medical Sciences, New Delhi, India

${ }^{5}$ Department of Neurosurgery, All India Institute of Medical

Sciences, Bhopal, Madhya Pradesh, India.

\author{
Address for correspondence Amit Agrawal, MCh, Department of \\ Neurosurgery, All India Institute of Medical Sciences, Saket Nagar, \\ Bhopal, Madhya Pradesh 462020, India \\ (e-mail: dramitagrawal@gmail.com).
}

\begin{abstract}
Keywords

- spinal cord injury

- spinal cord

- emergency

management

Spinal cord trauma constitutes one of the main causes of mortality and morbidity in young adults around the world, with an estimated 2 to 3 new cases for every 100,000 population. Road traffic accidents, falls from high heights, sports injuries, and violent actions are common causes of spinal cord injuries. There is no "gold standard" for the diagnosis of spinal cord traumatic injuries; however, the rational use of conventional radiologic test, computed tomography scan, and magnetic resonance imaging (MRI) will allow to identify almost all clinically relevant injuries. MRI is recommended according to surgeon's criteria, who after evaluating the specific characteristics of the injury will determine its usefulness. Therapeutic strategies need to be directed to maintain airway, breathing and circulation, maintenance of mean arterial pressure prevention of hypotension, and assessment of other associated injuries. Intensive treatment must be focused on the prevention and management of ventilatory and cardiovascular abnormalities related to muscle weakness and loss of autonomic innervation.
\end{abstract}

\section{Introduction}

Spinal cord trauma refers to injuries compromising vertebral column and spinal cord. Worldwide, it constitutes one of the main causes of mortality and morbidity, especially in young adults. It's estimated that every year there are 2 to 3 new cases for every 100,000 habitants, although incidence may vary depending on the regional variations. The clinical presentation is bimodal according to age, the first group is between 15 and 30 years of age, and it's generally caused by transit accidents, falls from high heights, sports injuries, and violent actions. The other peak of incidence is seen in population older than 65-years-old; it is seen in developed countries as life expectancy becomes higher. In this population, falls from great heights are more frequently cause of vertebral and cord injuries. ${ }^{1}$ Mortality of spinal cord trauma is highly variable, depending on several factors such as the relationship with the severity (American Spinal Injury Association [ASIA] A-C vs. D), the extension (local vs. in multiple levels) and the spinal segment injured, as well as the coexistence of additional distal injuries in the vertebral column and spinal cord. However, because of its hemodynamic and ventilatory repercussions, cervical and upper thoracic injuries more frequently require treatment in the intensive care unit (-Table $\mathbf{1}$ ).

\section{Initial Approach Including Immobilization}

In the primary evaluation of the patient in the intensive care unit, it's recommended to apply the consigned recommendations from the life support protocol for spinal cord traumatic injuries. ${ }^{3}$ These include "ABDC" evaluation, prioritizing airway permeability, ventilation, and
DOI https://doi.org/

10.1055/s-0040-1713556

ISSN 0973-0508.
CC2020 Neurotrauma Society of India
License terms

()(1) $\Theta \circledast$ 
Table 1 Physiopathology of spinal cord injury ${ }^{2}$

\begin{tabular}{|c|c|c|c|c|c|}
\hline & $\leq 2 \mathrm{~h}$ & $\leq 48 \mathrm{~h}$ & $\leq 14 \mathrm{~d}$ & $\leq 6 \mathrm{mo}$ & $\geq 6 \mathrm{mo}$ \\
\hline Phase & $\begin{array}{l}\text { Primary } \\
\text { immediate }\end{array}$ & Acute early & $\begin{array}{l}\text { Secondary } \\
\text { subacute }\end{array}$ & Intermediate & Chronic/late \\
\hline $\begin{array}{l}\text { Physiopathological } \\
\text { process }\end{array}$ & $\begin{array}{l}\text { Primary mechanic } \\
\text { injury } \\
\text { Gray matter } \\
\text { hemorrhage } \\
\text { Axonal } \\
\text { disconnection } \\
\text { Hemorrhagic } \\
\text { necrosis } \\
\text { Microglial } \\
\text { activation with } \\
\text { liberation of } \\
\text { cytokines } \\
\text { (IL-1 } \beta \text {, TNF } \alpha, \text { IL-6, } \\
\text { among others) }\end{array}$ & $\begin{array}{l}\text { Cytotoxic and } \\
\text { vasogenic edema } \\
\text { Production of } \\
\text { ROS: lipid } \\
\text { peroxidation } \\
\text { Excitotoxicity } \\
\text { mediated by } \\
\text { glutamate } \\
\text { Continuous } \\
\text { hemorrhages and } \\
\text { necrosis } \\
\text { Neutrophil infiltration } \\
\text { Loss of permeability } \\
\text { of blood-brain barrier } \\
\text { Early demyelination } \\
\text { (oligodendrocyte } \\
\text { apoptosis) } \\
\text { Neuronal death } \\
\text { Ischemic events } \\
\text { (systemic shock, } \\
\text { spinal shock, } \\
\text { hypotension, } \\
\text { hypoxia) }\end{array}$ & $\begin{array}{l}\text { Macrophages } \\
\text { infiltration } \\
\text { Astroglial } \\
\text { cicatrization } \\
\text { (reactive } \\
\text { astrocytosis) } \\
\text { Blood-brain } \\
\text { barrier repair } \\
\text { and resolution of } \\
\text { edema }\end{array}$ & $\begin{array}{l}\text { Astroglial scar } \\
\text { consolidation } \\
\text { Cyst formation } \\
\text { Stabilization of } \\
\text { injury }\end{array}$ & $\begin{array}{l}\text { Prolonged Wallerian } \\
\text { degeneration } \\
\text { Persistence of noninjured } \\
\text { and nondemyelinated } \\
\text { axons } \\
\text { Beginning of structural } \\
\text { plasticity and functional } \\
\text { processes in noninjured } \\
\text { medular tissue }\end{array}$ \\
\hline
\end{tabular}

Abbreviations: IL-6, interleukin-6; IL-1 $\beta$, interleukin-1 beta; ROS, reactive oxygen species; TNF- $\alpha$, tumor necrosis factor-alpha.

circulation, while spinal immobilization measures are established. ${ }^{4-6}$ To immobilize the vertebral column, a cervical rigid neck brace, cephalic immobilization, and spinal board must be used for all unconscious patients, as well as for conscious patients referring spinal pain. Immobilizations must be maintained until any spinal or medullary injury is discarded or when definitive treatment is given. ${ }^{6-8}$ Patients at risk of vertebral column injury are those who present any of the following conditions:

- Altered mental status

- Intoxication

- Spinal pain or deformity

- Suspected limb fracture or suspected distraction injuries (long bones fractures, visceral injuries that require surgical evaluation, extensive burns, superior thorax injuries, lacerations, abrasions or extensive crushing; any injury that causes acute functional alteration that prevents physical, mental, or neurologic examination)

- Patients with focal neurological deficits

However, those patients who are conscious, alert, symptomatic, without cervical pain, without sensorial or motor anomalies or any other injuries that alter the physical examination, may be transported without cervical immobilization; this facilitates airway manipulation and ventilation, and decreases the risk of aspiration. Immobilization is not recommended in penetrating injuries, because the probability of cervical instability is quite low and may delay resuscitation. ${ }^{9}$
The second phase of evaluation is focused on distinguishing the spinal or medullary injuries. The whole vertebral column and prespinal muscles must be visualized and palpated in search of deformities or local pain. The presence of tympany may be suggestive of medullary injury. ${ }^{9}$ The findings in the neurological examination must be compared with the medullary disability and standardized classification scale proposed by The ASIA that includes standardized neurological classification of spinal injuries into category A (complete); categories B, C, and D (incomplete); and category $\mathrm{E}$ (normal). ${ }^{10}$ According to the findings of the neurologic examination, the spinal injuries may be classified in some of the following clinical syndromes, that is, complete transection syndrome, hemisection syndrome or Brown-Séquard syndrome, central cord syndrome or Schneider's syndrome, anterior medullary syndrome, central cord syndrome, and cauda equina syndrome.

Additionally, the probable injury level must be identified clinically, because of the strong implications in the radiologic evaluation, management, and prognosis. Neurologic evaluation has to be repeated daily during the first 72 hours after the injury, because this is the time when major changes are seen. In the patients with complete medullary section syndrome, during the first 3 to 5 days after the injury, myotatic reflexes may be lost. This period of time is known as medullary shock (this is not the same as a neurogenic shock of medullary origin), whose outcome is clinically determined by the return of the bulbocavernosus reflex (Osinski reflex). If complete medullary section syndrome 
findings are persistent even when the bulbocavernosus reflex has returned, the probability of neurologic recovery is very low.

\section{Imaging Evaluation}

There is no "gold standard" for the diagnosis of spinal cord traumatic injuries; however, the rational use of conventional radiologic tests, computed tomography (CT) scan, and magnetic resonance imaging (MRI) allows identifying almost all clinically relevant injuries. Currently, the most recommended method to identify vertebral injuries is CT scan, because of its availability, sensibility, and specificity; on the other hand, conventional radiology techniques must be considered as a diagnostic approach only when CT scan is not available. ${ }^{11}$ Imaging studies indication must be based on the clinical finding of the patient. In those patients who are conscious and show sensitive response, the approach will be made considering that the sensitive level secondary to cervical injuries is above the injured segment; in upper thoracic segments, one level below; in lower thoracic segments, two segment below; and those in the medullary cone and cauda equina produce well defined syndromes. However, all vertebral segments caudal to the neurologic injury must be examined systematically. In those patients with an altered state of consciousness (i.e., moderate and severe cranioencephalic trauma, intoxication, shock and so on), examination of the vertebral column by $\mathrm{CT}$ is indicated. For the assessment of cervical column, a three-projection radiography (anterior-posterior, lateral, and odontoid) technique is recommended only when CT is not available; if any anomaly is found or if bone structures are hardly distinguished, the assessment must be complemented with CT scan. ${ }^{11}$ MRI is a key element in patients whose neurologic examinations is altered, since it allows diagnosing medullary injuries, which are seen as increase in signal in the sequence $\mathrm{T} 2$, and distinguishing epidural collections, and discoligamentous complex injuries that may cause medullary compression or mechanical instability; this findings may result useful to determine the treatment of the injury. In those patients who do not present neurologic deterioration, MRI is recommended according to surgeon's criteria, who after evaluating the specific characteristics of the injury will determine its usefulness.

\section{Treatment}

In the emergency management, therapeutic actions should look for the following principles:
1. Maintain ventilator function, and treat its respective alterations.
2. Identify and treat hemodynamic alterations.
3. Stop deterioration of neurologic damage.
4. Prevent systemic complications.
5. Promote early rehabilitation.

\section{Respiratory Care}

Respiratory alterations are the principal cause of death in patients with spinal cord injury (SCI), that's why the standardized approach is vital, as this is associated with a lower incidence of complications, fewer days with mechanical ventilation, intensive care unit stay, and lower attention costs. ${ }^{12}$ The majority of patients with high quadriplegia will present respiratory alterations due to compromise of diaphragmatic innervation (C-C-5) since the beginning, or will develop it in the first 5 days after the traumatic event secondary to ascending medullary edema. ${ }^{13}$ Therefore, respiratory management of these patients generally includes intubation, mechanical ventilation, and tracheostomy, especially when the injury is found above C5 level. ${ }^{12}$ It's very important to note that during rapid sequence intubation, succinylcholine must be avoided during the first 48 hours due to the high risk of lethal hyperkalemia. ${ }^{13}$ In those patients who do not present respiratory failure at admission, an integral assessment of ventilatory mechanic must be performed; this includes physical examination and measurement of forced expiratory volume in 1 second, forced vital capacity and peak expiratory flow, which will be used to monitor the respiratory mechanic daily and allow anticipation of respiratory failure. For atelectasis prevention, in intubated patients relatively high volumes of air (10-15 mL/kg) should be considered to solve or to prevent atelectasis; in nonintubated patients the use of respiratory incentives is recommended every hour. Tracheostomy with chronic airway management may be used in patients with persistent respiratory compromise and unmanageable airway secretions..$^{14}$ For patient whose injury is above $\mathrm{C} 5$ level, a diaphragmatic pacemaker implant should be considered because diaphragmatic weakness secondary to denervation and muscular atrophy is the main cause of respiratory failure in these types of patients.

\section{Cardiovascular and Hemodynamic Care}

Therapeutic strategies need to be directed to maintain mean arterial pressure between 85 and $90 \mathrm{~mm} \mathrm{Hg}$ during the first 7 days after the traumatic event to guarantee medullary perfusion. ${ }^{15}$ In patients who present with hypotension, fluid resuscitation must be optimized, rule out other injuries as potential cause of hypotension and if the goal arterial pressure is not achieved, norepinephrine infusion must be started with a dose of $0.05 \mu \mathrm{g} / \mathrm{kg} / \mathrm{min}$, which will be entitled to guarantee medullary perfusion. However, fluid resuscitation must be performed carefully to avoid fluid overload in these patients with high risk of pulmonary edema..$^{16}$ Some patients with upper thoracic or cervical injuries may present sympathetic insufficiency, which may present as extreme symptomatic bradycardia that can progress to cardiac arrest; because of this, such alterations require observation and appropriate treatment with chronotropic drugs (atropine or adrenaline). Some refractory cases will need to be treated with temporal transthoracic or transvenous pacemakers. 


\section{Gastrointestinal Care}

The start of enteral nutrition must be early, preferably before 72 hours after the traumatic event. ${ }^{17}$ Prophylaxis for stress-induced gastric mucous ulcers is indicated in all patients with thoracic or cervical injuries, as well as in those with mechanical ventilation. Routinely it's recommended the use of proton-pump inhibitors or $\mathrm{H} 2$ receptor antagonist, which will be suspended only once mechanical ventilation is suspended as well and enteral intake goals have been accomplished for at least 48 hours. Gastric emptying delay manifests as nausea, vomiting, and abdominal distension. In the patients with a tube for enteral nutrition, the gastric residue should be monitored strictly every 4 hours, and should never be more than $250 \mathrm{~mL}$. In the event that gastric emptying is delayed, it is recommended to start treatment with metoclopramide and erythromycin, and in case of persistence, progress the nasogastric tube to post-pyloric tube. The first measure to avoid constipation is prevention by digital stimulation and laxative drug such as bisacodyl at a dose of $10 \mathrm{mg}$ once daily. In those cases, in which defecation is not accomplished 72 hours after the initial dosage, the dose may be increased up to $10 \mathrm{mg}$ bid and sorbitol ( $30 \mathrm{~mL}$ bid PO or nutrition tube) may be added.

\section{Urogenital Care}

In the initial medullary shock phase, the spinal reflex activity in the areas below the injury stops completely; this is translated as lower urinary tract areflexia that implies neurogenic bladder with passive filling and overflow incontinence. ${ }^{5}$ The duration of this stage is variable from days to weeks before the bladder reflex activity is restored. ${ }^{5,18}$ In the acute phase, once the presence of clinical signs suggestive of urethral trauma (urinary meatus bleeding, vaginal introitus bleeding, hematuria, free-floating prostate, perineal hematoma) have been ruled out, an imminent vesical catheterization should be performed, this procedure is associated with a lower incidence of urinary tract infections, compared with permanent catheterization; thus, it constitutes the election method in patients with SCI. ${ }^{5}$ Other options are associated with less risk of urinary tract infection such as "urofunda" (urologic sheath) or bladder training. ${ }^{18}$

Priapism is another acute and generally auto-limited event, caused by an increase of the arterial blow flow in the cavernous sinusoids with oxygenated blood overload without causing ischemia or acidosis therefore, sequels are rare. It solves spontaneously in $62 \%$ of patients within a maximum period of 5 hours with no need of specific treatment. It's managed with conservative treatment with topical application of ice in the perineum. Measures such as drainage of the corpus cavernosum penis, intracavernous injection of $\alpha$-adrenergic drugs (phenylephrine, adrenaline), are not recommended. ${ }^{18}$

\section{Venous Thromboembolic Disease Prophylaxis}

The incidence of deep venous thrombosis in patients with SCI varies from 9 to $100 \%$. The strategies used for prevention in thromboprophylaxis include low-molecular-weight-heparin (LMWHs), unfractionated heparin, antithrombotic stockings, intermittent pneumatic compression devices, and inferior vena cava filters. The current recommendation is the start of early antithrombotic prophylaxis ( $<72$ hours) and combined that includes a LMWH, which must be used in association with intermittent pneumatic compression devices and electric stimulation, because drug prophylaxis alone is poorly effective. Unfractionated heparin should be used for cases where LMWH is not available or contraindicated. ${ }^{19}$ In the patients that require surgical treatment, LMWH must be suspended 12 hours before the programmed surgery and restarted in the 24 hours posterior to the surgery. ${ }^{20}$ The recommended duration of thromboprophylaxis is 3 months.

\section{Conclusions}

The initial approach of the patient requires optimization of vital signs (arterial pressure, ventilation, and oxygenation), as seen in the protocols for polytraumatized. Immobilization must be used routinely in patients with suggestive findings of spinal injury and in those whose clinical examination is nonreliable until injuries can be ruled out with imaging studies. In those patients that require imaging assessment and do not present neurologic deterioration, CT scan is the election imaging study; while those patients who present findings suggestive of neurologic injury have to be assessed additionally with MRI. In the actuality, there is no pharmacological treatment that is useful to improve the functional prognosis of patients with traumatic medullary injuries. Steroids (methylprednisolone) don't improve vital or functional prognosis and may cause severe complications, even fatal outcome. ${ }^{21}$ Intensive treatment must be focused on the prevention and management of ventilatory and cardiovascular abnormalities related to muscle weakness and loss of autonomic innervation. A huge percentage of morbidity and mortality is related to gastrointestinal and urinary alterations and venous thromboembolic disease, so the treatment of these alterations should be established promptly in the acute phase of the traumatic event.

\section{Conflict of Interest}

None declared.

\section{References}

1 Lee BB, Cripps RA, Fitzharris M, Wing PC. The global map for traumatic spinal cord injury epidemiology: update 2011, global incidence rate. Spinal Cord 2014;52(2):110-116

2 Rowland JW, Hawryluk GW, Kwon B, Fehlings MG. Current status of acute spinal cord injury pathophysiology and emerging therapies: promise on the horizon. Neurosurg Focus 2008;25(5):E2 
3 Stein DM, Roddy V, Marx J, Smith WS, Weingart SD. Emergency neurological life support: traumatic spine injury. Neurocrit Care 2012;17(Suppl 1):S102-S111

4 Schouten R, Albert T, Kwon BK. The spine-injured patient: initial assessment and emergency treatment. J Am Acad Orthop Surg 2012;20(6):336-346

5 Singh R, Rohilla RK, Sangwan K, Siwach R, Magu NK, Sangwan SS. Bladder management methods and urological complications in spinal cord injury patients. Indian J Orthop 2011;45(2):141-147

6 Consortium for Spinal Cord Medicine. Early acute management in adults with spinal cord injury: a clinical practice guideline for health-care professionals. J Spinal Cord Med 2008;31(4):403-479

7 Schmidt OI, Gahr RH, Gosse A, Heyde CE. ATLS(R) and damage control in spine trauma. World J Emerg Surg 2009;4:9

8 Ahn H, Singh J, Nathens A, et al. Pre-hospital care management of a potential spinal cord injured patient: a systematic review of the literature and evidence-based guidelines. J Neurotrauma 2011;28(8):1341-1361

9 Theodore N, Hadley MN, Aarabi B, et al. Prehospital cervical spinal immobilization after trauma. Neurosurgery 2013; 72(Suppl 2):22-34

10 Association ASI, International Standards for Neurological Classification of Spinal Cord Injury. Chicago: ASIA; 2015

11 Ryken TC, Hadley MN, Walters BC, et al. Radiographic assessment. Neurosurgery 2013;72(Suppl 2) :54-72

12 Berney S, Bragge P, Granger C, Opdam H, Denehy L. The acute respiratory management of cervical spinal cord injury in the first 6 weeks after injury: a systematic review. Spinal Cord 2011;49(1):17-29

13 Jia X, Kowalski RG, Sciubba DM, Geocadin RG. Critical care of traumatic spinal cord injury. J Intensive Care Med 2013;28(1):12-23

14 Shank CD, Walters BC, Hadley MN. Management of acute traumatic spinal cord injuries. Handb Clin Neurol 2017;140:275-298

15 Ryken TC, Hurlbert RJ, Hadley MN, et al. The acute cardiopulmonary management of patients with cervical spinal cord injuries. Neurosurgery 2013;72(Suppl 2):84-92

16 Witiw CD, Fehlings MG. Acute spinal cord injury. J Spinal Disord Tech 2015;28(6):202-210

17 Dhall SS, Hadley MN, Aarabi B, et al. Nutritional support after spinal cord injury. Neurosurgery 2013;72(Suppl 2):255-259

18 Todd NV. Priapism in acute spinal cord injury. Spinal Cord 2011;49(10):1033-1035

19 Kessler TM, Traini LR, Welk B, Schneider MP, Thavaseelan J, Curt A. Early neurological care of patients with spinal cord injury. World J Urol 2018;36(10):1529-1536

20 Dhall SS, Hadley MN, Aarabi B, et al. Deep venous thrombosis and thromboembolism in patients with cervical spinal cord injuries. Neurosurgery 2013;72(Suppl 2):244-254

21 Hurlbert RJ, Hadley MN, Walters BC, et al. Pharmacological therapy for acute spinal cord injury. Neurosurgery 2013; 72(Suppl 2):93-105 